\title{
PHYSICAL PROPERTIES OF SPUTTERED GERMANIUM-DOPED INDIUM TIN OXIDE FILMS (ITO : GE) OBTAINED AT LOW DEPOSITION TEMPERATURE
}

\author{
S.J. WEN, G. CAMPET, AND J.P. MANAUD \\ Laboratoire de Chimie du Solide du CNRS, Université Bordeaux I, 351 Cours de la Libération, 33405 \\ Talence (France) \\ (Received June 14, 1992; in final form August 6, 1992)
}

Undoped and Ge-doped ITO films (ITO: Ge) deposited at low temperature $\left(70^{\circ} \mathrm{C}\right.$ ) have been studied. Although both samples have the same carrier concentration, a higher carrier mobility occurs for ITO: Ge. An evaluation of the relative position of the dopant associated energy states has been carried out.

\section{INTRODUCTION}

Indium tin oxide compositions, commonly labeled ITO, are used in thin film form are utilized in various applications including transparent heat reflectors, heterogeneous solar cells, and transparent conductive coating for electrochromic windows ("smart windows").

Moreover, the burgeoning popularity of lightweight display has forced manufacturers to consider the use of plastic materials in their products. Advances in plastic roll-coating technology, particularly the use of high-rate sputter deposition in roll coaters, have resulted in the development of ITO coatings on polymer films such as polyester and polycarbonate [1].

However, a low temperature deposition process $\left(\mathrm{T}_{\text {substrate }} \leq 100^{\circ} \mathrm{C}\right)$ is necessary to coat plastic substrates and, therefore, the corresponding ITO films are only partially crystallized with an average grain size lower than $100 \AA[2,3$ and note (*) below].

These ITO films, deposited at low temperature, can exhibit a good transparency in the whole visible region $(80 \leq \mathrm{T} \% \leq 85)$; unfortunately their resistivity is higher than about $10^{-3} \Omega^{-1} \mathrm{~cm}^{-1}[1,3]$. Therefore, they cannot efficiently be used in displays, (i.e., "soft" solar cells or electrchromic systems), requiring highly transparent films, with low resistances, coated on plastic substrates.

\footnotetext{
* On the other hand, the grain size of crystallized ITO films, sputtered on heated substrates $(T \geq$ $\left.450{ }^{\circ} \mathrm{C}\right)$ or annealed after sputtering $\left(T \geq 500^{\circ} \mathrm{C}\right)$, ranges typically between 400 and $600 \AA[3,4]$. For similar compositions the electrical and optical properties of the crystallized ITO films appear to be independent of the orientation of the crystallites $[5,6]$.
} 


\section{NEW APPROACHES TO DECREASE THE RESISTIVITY OF HIGHLY TRANSPARENT ITO FILMS, DEPOSITED AT LOW TEMPERATURES}

Two approaches can be followed: a "textural approach" and an "electronic approach".

\section{II.1. The "Textural-approach"}

It must be emphasized that the density of the ITO-based films deposited at low substrate temperature should approach, as much as possible, the theoretical density in order to diminish sufficiently the carrier-scattering-effect occuring at grain boundaries and related to the micropore sizes.

Indeed such a scattering effect can cause a decrease of the carrier mobility and conductivity, particularly if the average crystallite size is small $(<100 \AA)[2,3,7]$.

We have recently shown that this scattering effect can be reduced (and the conductivity increased) by doping ITO with copper oxide: this results in an enhancement of the sample density and, therefore, of the carrier tunneling through the micropores [8].

\section{II.2. The "Electronic Approach"}

This second approach is based on the fact that heavily $n$-type $\left(\mathrm{n}>10^{20} \mathrm{~cm}^{-3}\right)$ films are required in order to minimize the thicknes $(<20 \AA)$ of the depletion layer width occuring at the crystallite surface. The carrier-tunneling through the depletionlayer would then be enhanced $[3,7]$. This situation differs from the previous one, which was related to micropores (II.1.).

On the other hand, Hoffman and al. $[9,10]$ have shown that, for sputtered highly degenerated ITO films $\left(\mathrm{n}>10^{20} \mathrm{~cm}^{-3}\right)$, the conduction-band electrons are strongly scattered at the ionized donor centers.

However, such a scattering effect (which, obviously, also inhibits the carrier mobility) should, a priori, be partially weakened if more appropriate n-type dopants are used to partially or totally substitute for tin in ITO. In fact these dopants $\mathrm{M}^{(\mathrm{m}-\mathrm{n})+}$ should, ideally, be such as the ground energy states associated with the oxidized donor centers $\mathrm{M}^{\mathrm{m}+}$ gives:

$\mathrm{M}^{(\mathrm{m}-\mathrm{n})+} \longrightarrow \mathrm{M}^{\mathrm{m}+}+\mathrm{ne}^{-}[$C.B. $]$

where $\mathrm{e}^{-}$[C.B.] symbolizes the conduction-band electrons and are located in the conduction band in order to minimize their interaction with the carriers.

On the other hand, a valuation of the "electron-acceptor-strength" of the ionized doping elements, $\mathrm{M}^{\mathrm{m}+}$, can be carried out using the empirical relationship established by Y. Zhang [11]:

$\mathrm{L}=\frac{\mathrm{Z}}{\mathrm{r}_{\mathrm{k}}^{2}}-7.7 \mathrm{X}_{\mathrm{z}}+0.8$ 
where L symbolizes the "lewis acid strength" of the element. $\mathrm{Z} / \mathrm{r}_{\mathrm{k}}^{2}$ (where $\mathrm{Z}$ is the charge number of the atomic core and $r_{k}^{2}$ is the ionic radius) is related to electrostatic force and $\mathrm{X}_{\mathrm{z}}$ symbolizes the electronegativity of elements in valence states.

We have indeed reported elsewhere [12] that the "electron-acceptor strength" of the ionized donor centers, $\mathrm{M}^{\mathrm{m}+}$, decreases as the "Lewis acid strength", $\mathrm{L}$, of the element increases. Consequently, high mobilities, and thereby high conductivities, are likely to occur for ITO (or IO) samples heavily doped with donor centers having high $\mathrm{L}$ values, particularly in their oxidized form.

\section{STRATEGY ADOPTED}

The most transparent-conductive ITO based films should result from the combination of the two above-mentioned approaches. However, we will focus only on the "electronic approach" for sake of clarity.

Following the guiding lines of the "electronic approach" it appears that:

(i) We have to focus on ITO-based films (deposited at low substrate temperature) having high carrier concentration $\left(\mathrm{n}>10^{20} \mathrm{~cm}^{-3}\right)$.

(ii) The use of $\mathrm{Ge}^{2+},\left(\mathrm{Ge}^{2+} \rightarrow \mathrm{Ge}^{4+}+2 \mathrm{e}^{-}(\mathrm{CB})\right)$, instead of $\mathrm{Sn}^{2+},\left(\mathrm{Sn}^{2+} \rightarrow\right.$ $\left.\mathrm{Sn}^{4+}+2 \mathrm{e}^{-}(\mathrm{CB})\right)$, as $\mathrm{n}$-type doping element in ITO would be judicious. Indeed one has [11]

$\mathrm{L}\left(\mathrm{Ge}^{2+}\right) \cong \mathrm{L}\left(\mathrm{Sn}^{2+}\right)$

but, most interestingly [11]

$\mathrm{L}\left(\mathrm{Ge}^{4+}\right) \gg \mathrm{L}\left(\mathrm{Sn}^{4+}\right)$

Consequently the carrier mobility should be higher for ITO:Ge films than for ITO films, at least for samples having similar carrier concentration (i), compacity (ii) and average crystallite size (iii).

We will then focus here on two types of films, ITO films and ITO:Ge films, sputtered at low substrate temperature $\left(70^{\circ} \mathrm{C}\right)$ using:

- similar experimental procedures in order to fulfill points (ii) and (iii).

- appropriate target compositions in order to obtain films having the same carrier concentration (point fulfilling (i)).

Let us point out that we do not intend to optimize the composition of the ITO: Ge films. Our main aim is to get insight into the influence of Ge doping upon the carrier mobility and, thereby, upon the conductivity of the ITO based films.

\section{FILM PREPARATION.}

The films were deposited on non-heated substrates, using RF-magnetron-cathodic deposition technique with home-made targets (Table 1). 


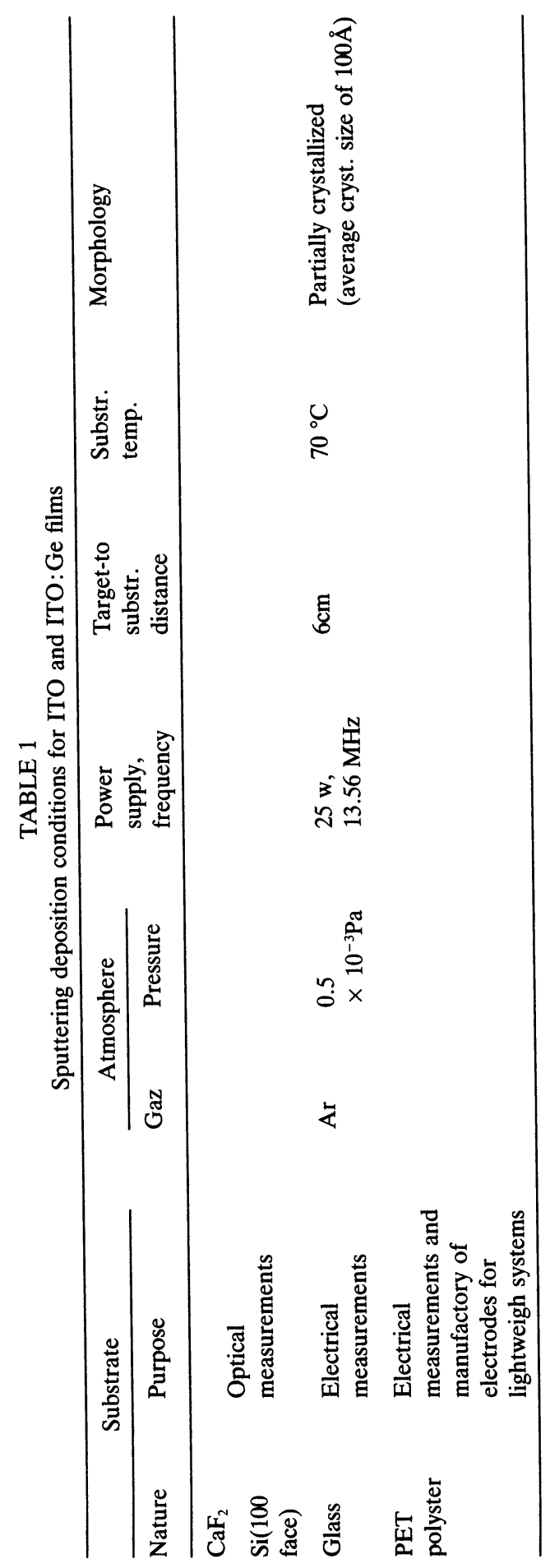


TABLE 2

Target and film compositions for ITO (a) and ITO:Ge (b).

\begin{tabular}{llll}
\hline ITO & $\mathrm{In} / \mathrm{Sn}( \pm 1)$ & $\mathrm{O} / \mathrm{In}( \pm 0.1)$ & $\mathrm{O} / \mathrm{Sn}( \pm 2)$ \\
\hline Target & 10 & 1.7 & 15 \\
Film & 15 & 1.6 & 23 \\
\hline
\end{tabular}

(a)

\begin{tabular}{llllll}
\hline ITO:Ge & $\mathrm{In} / \mathrm{Sn}( \pm 1)$ & $\mathrm{In} / \mathrm{Ge}( \pm 2)$ & $\mathrm{O} / \mathrm{In}( \pm 0.1)$ & $\mathrm{O} / \mathrm{Sn}( \pm 2)$ & $\mathrm{O} / \mathrm{Ge}( \pm 2)$ \\
\hline Target & 12 & 17 & 1.7 & 18 & 29 \\
Film & 15 & 34 & 1.7 & 26 & 62 \\
\hline
\end{tabular}

(b)

Among all the films deposited, only those whose composition is reported in Table 2 have been selected here, for sake of clarity, because they have similar carrier concentrations as will be shown below. The compositions have been established from Rutherford Back scattering, Auger spectroscopy and Castaing microproble analyzer.

\section{ELECTRICAL AND OPTICAL MEASUREMENTS}

Electrical properties were studied under vacuum $\left(10^{-3} \mathrm{~Pa}\right)$ immediately after film deposition in order to minimize any aging effect (\$II.2.).

Accurate values of mobility and carrier concentration were obtained using the a.c. Van der Pauw method (1.2 T magnetic field). Silver paste ensured electrical contacts.

The optical absorption spectra were recorded with a Cary 17 ratio-recording spectrophotometer.

\section{RESULTS AND DISCUSSION}

\section{VI.1. Temperature Dependence of Conductivity; Free Carrier Concentration and Mobility}

Figure 1 illustrates the temperature dependance of conductivity for ITO and ITO:Ge films. Below $600 \mathrm{~K}$ the conductivity increases with the temperature probably because of the increase of the crystallite size [3]. The grain boundary scattering effect of the conduction band electrons is still non-negligible, particularly at room temperature, in spite of the high carrier concentrations occuring in the films $(\mathbf{n}=$ $4.2 \times 10^{20} \mathrm{~cm}^{-3}$ : Table 3 ). Hopefully the grain boundary effect does not entirely mask the Ge doping effect since the ITO:Ge films clearly exhibits a higher carrier mobility than ITO (Table 3). 


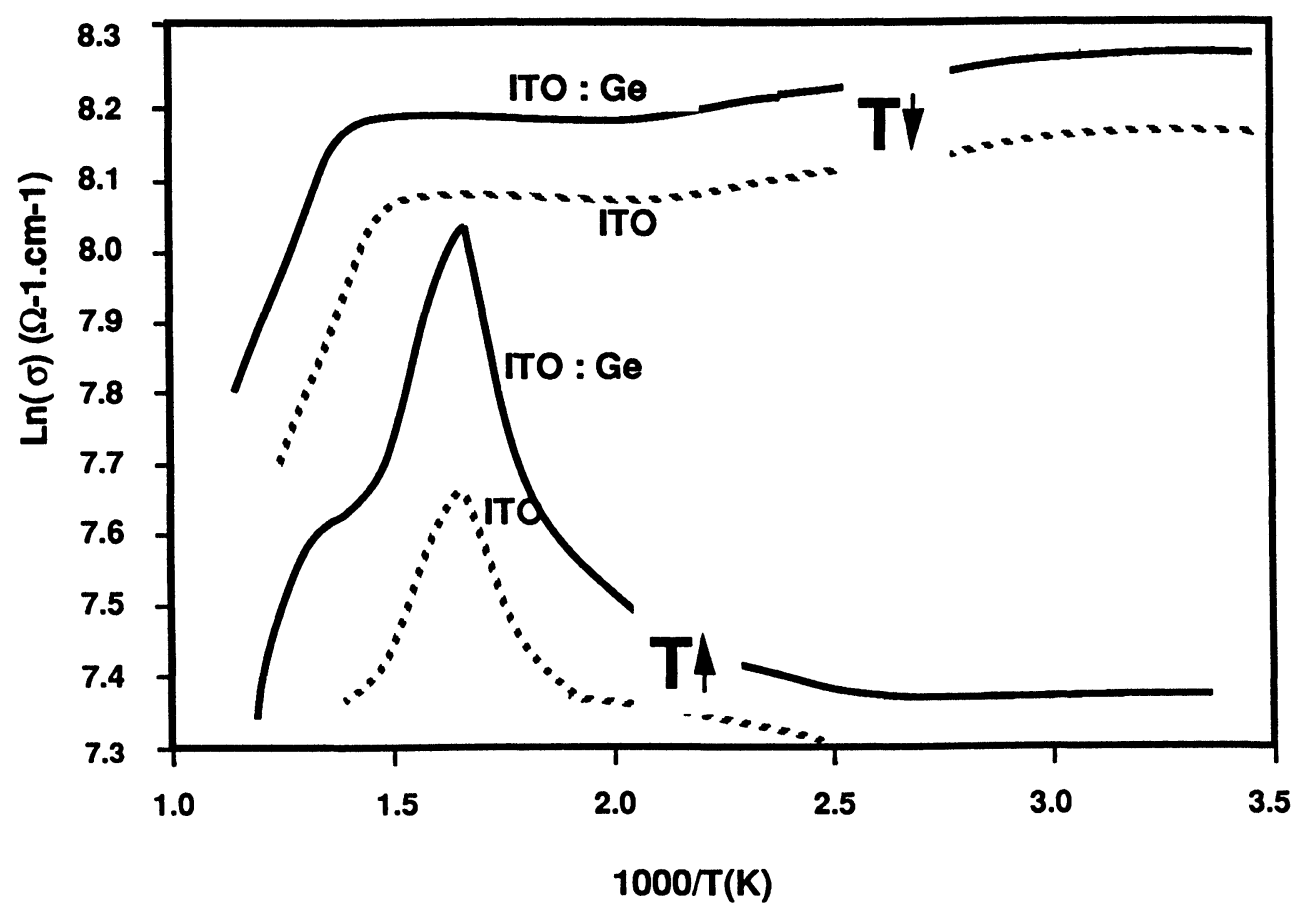

FIGURE 1 Influence of the arrangement of crystallite size on the conductivity for ITO and ITO:Ge films deposited on glass substrates.

Consequently a $\mathrm{R} \diamond$ value of $30 \mathrm{ohm} . /$ sq. only occurs for 2000 - $\AA$ thick ITO: Ge films.

\section{VI.2. Visible Light Transmission}

As shown in Fig. 2, the ITO: Ge films exhibit a slightly higher transparency in the visible region than the ITO films, although they may have a lower carrier effective

TABLE 3

Values of room temperature conductivity $\left(\sigma\left(25^{\circ} \mathrm{C}\right)\right)$, carrier concentration $\left(\mathrm{n}\left(25^{\circ} \mathrm{C}\right)\right)$ and mobility $\left(\mu\left(25^{\circ} \mathrm{C}\right)\right)$ for ITO and ITO: Ge films deposited at low temperature $\left(\mathrm{T}_{\text {substr. }}=70^{\circ} \mathrm{C}\right)$.

\begin{tabular}{lll}
\hline Substrates & \multicolumn{2}{c}{ Glass or PET polyster } \\
\cline { 2 - 3 } & ITO & ITO:Ge \\
\hline Film thickness $(\AA)$ & 2000 & 2000 \\
$\sigma\left(25^{\circ}\right)\left(\Omega^{-1} \mathrm{~cm}^{-1}\right)$ & 1000 & 1500 \\
$\mathrm{n}\left(25^{\circ}\right)\left(\mathrm{cm}^{-3}\right)$ & $4.2 \times 10^{20}$ & $4.2 \times 10^{20}$ \\
$\mu\left(25^{\circ}\right)\left(\mathrm{cm}^{-2} \cdot \mathrm{V}^{-1} \cdot \mathrm{s}^{-1}\right)$ & 15 & 23 \\
$\mathrm{R} \diamond(\mathrm{ohm} . / \mathrm{sq})$. & 50 & 30 \\
\hline
\end{tabular}




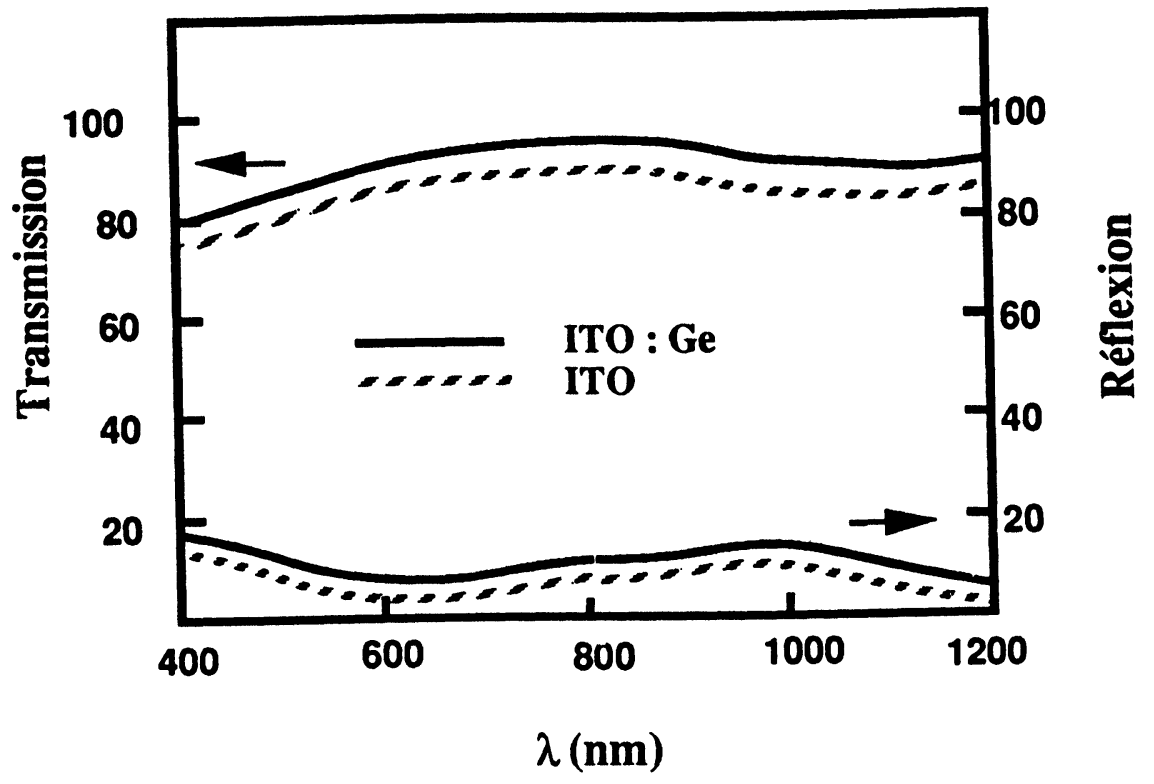

FIGURE 2 Transmission and reflexion spectra of 2000 thick ITO and ITO:Ge films deposited on glass substrates.

mass, $\mathrm{m}^{*},[12]$. In fact the significantly higher carrier mobility observed for ITO: Ge films (Table 3) should account for their higher transparency since [4]:

$\mu \propto \lambda^{2} / \mathrm{m}^{*} \mathrm{~A}_{\text {free }}$ carriers

where $A_{\text {free }}$ carriers symbolizes the photon loss due to free carrier absorption and $\lambda$ is the photon wavelength.

\section{CONCLUSION}

We have shown that the carrier mobility for ITO:Ge is higher than for ITO, at least for samples having similar carrier concentration, compacity and average crystallite size. Therefore, the conductivity of ITO films can be improved by doping with $\mathrm{Ge}$, which does not affect the film transparency.

\section{ACKNOWLEDGEMENTS}

The authors wish to thank Pr. G. COUTURIER for helpful assistance.

\section{REFERENCES}

1. L.A. Hoittand and J.B. Fenn, Photonics Spectra, 65, Oct. (1986).

2. G. Campet, C. Geoffroy, and J. Portier, Mat. Science and Eng., B8, 45 (1991).

3. C. Geoffroy, Doct. Thesis, Bordeaux University (France), (1990). 
4. K.L. Chopra, S. Major, and D.K. Pandya, Thin Solid Films, 102, 1 (1983).

5. J.C.C. Fan and F.J. Bachner, J. Electrochem. Soc., 112, 1719 (1975).

6. C.C. Fan, F.J. Bachner, and G.H. Foley, Appl. Phys. Lett., 31, 773 (1977).

7. S.J. Wen, Doct. Thesis Bordeaux University (France), (1992).

8. S.J. Wen, G. Couturier, G. Campet, J. Portier, and J. Claverie, proposed to Mat. Science and Eng., B (1991).

9. H. Hoffmann, J. Pickl, M. Schmidt, and D. Krause, Appl. Phys. 16, 239 (1978).

10. H. Hoffmann, A. Dietrich, J. Pickl, and D. Krause, Appl. Phys. 16, 381 (1978).

11. Zhang, Inorg. Chem. 21, 3386 (1982).

12. S.J. Wen, G. Campet, and J. Portier, J. Goodenough Mat. Science and Eng., B (accepted 1992). 

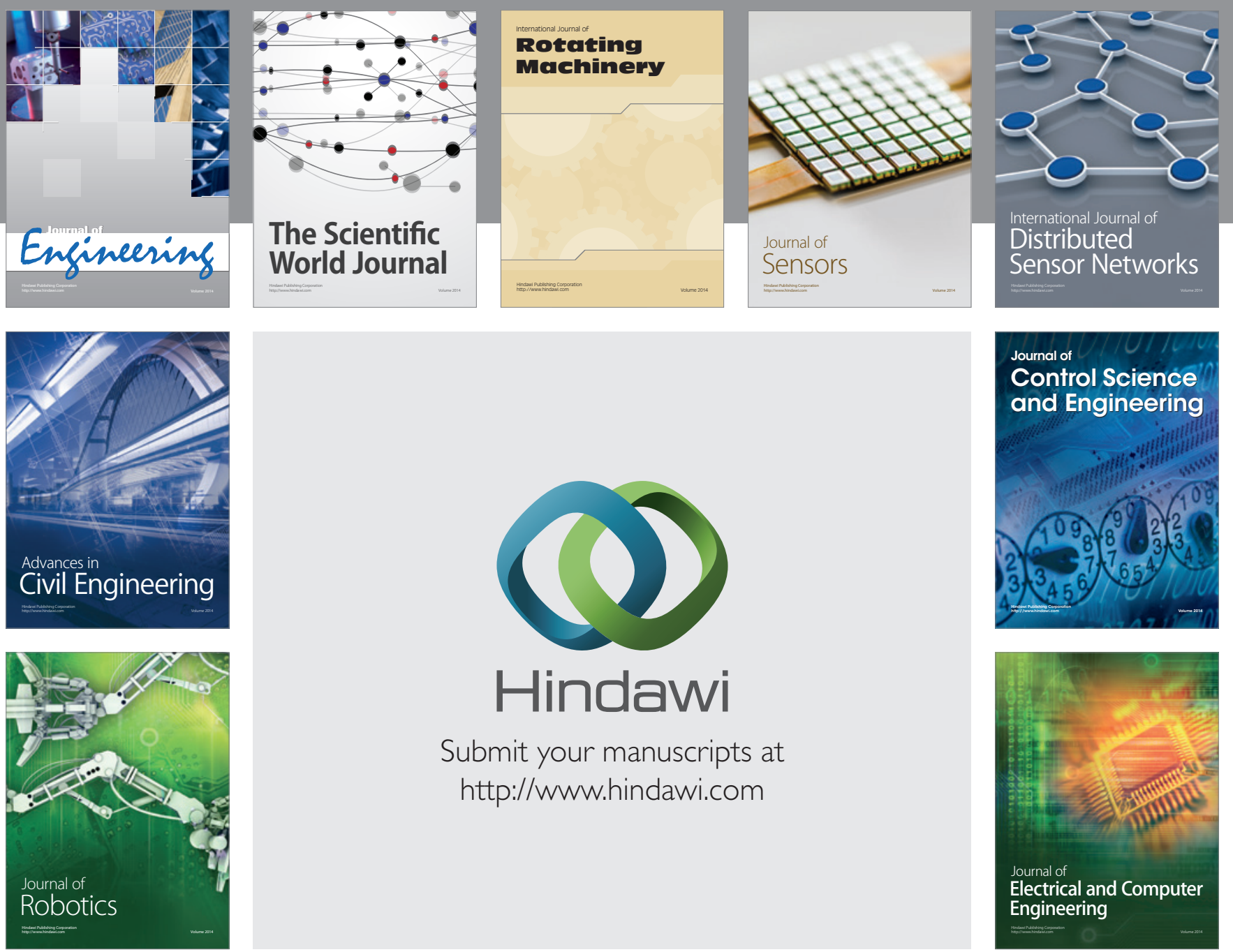

Submit your manuscripts at

http://www.hindawi.com
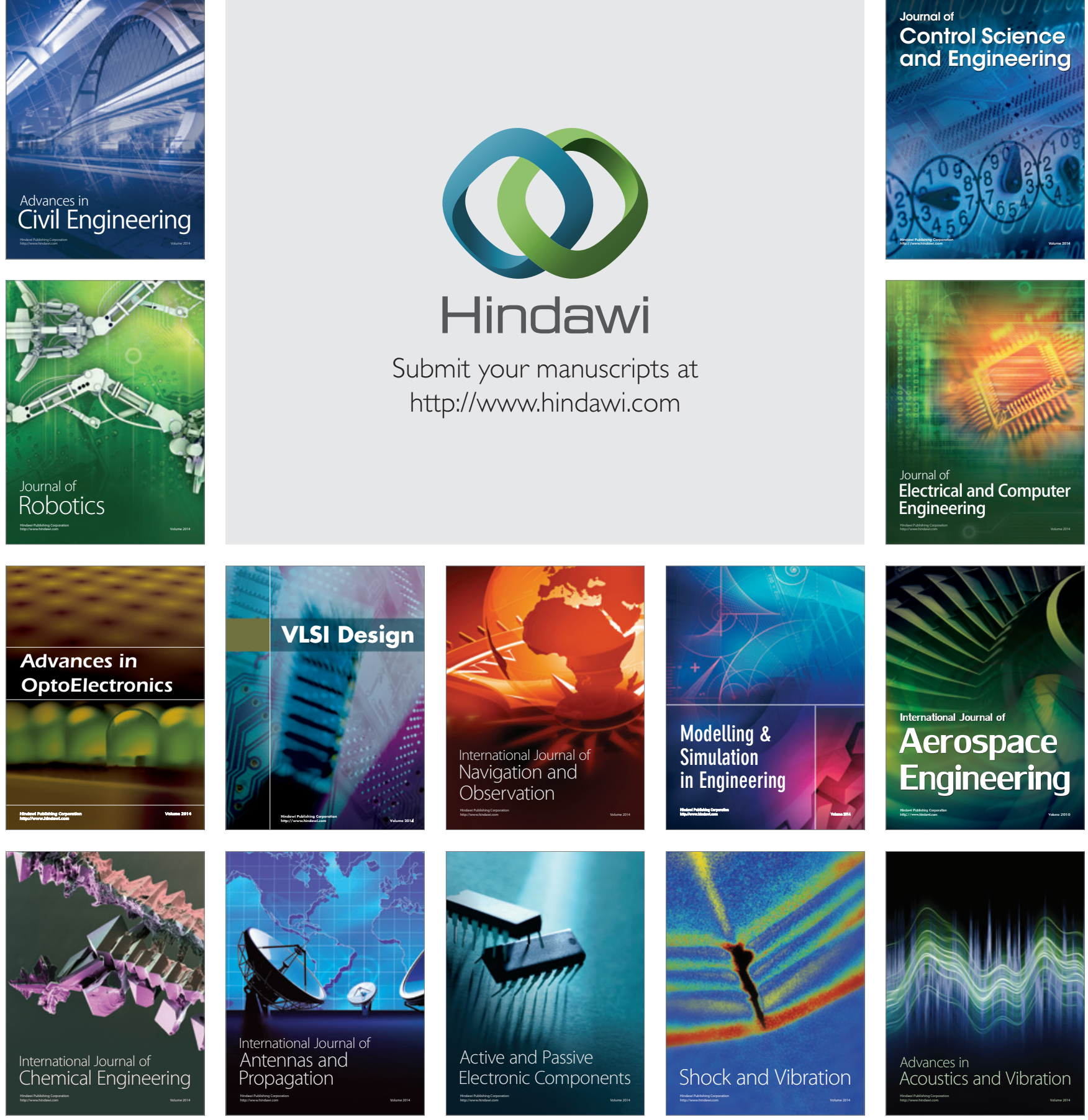